\title{
Evaluation of breastfeeding attitudes and education of Greek gynecology professionals to improve the educational curriculum of Obstetrics \& Gynecology Departments
}

\section{Theodoros Theodoridis}

Aristotle University of Thessaloniki School of Medicine: Aristoteleio Panepistemio Thessalonikes

Tmema latrikes

Eleftherios Vavoulidis ( $\square$ e.vavoulidis@outlook.com )

Aristotle University of Thessaloniki https://orcid.org/0000-0002-3577-8782

\section{Konstantinos Dinas}

Aristotle University of Thessaloniki School of Medicine: Aristoteleio Panepistemio Thessalonikes

Tmema latrikes

\section{Evagelia Saranti}

General Hospital of Thessaloniki Papageorgiou: Geniko Nosokomeio Thessalonikis Papageorgiou

\section{Evagelia Voziki}

General Hospital of Thessaloniki Papageorgiou: Geniko Nosokomeio Thessalonikis Papageorgiou

Stella lliaskou

General Hospital of Thessaloniki Papageorgiou: Geniko Nosokomeio Thessalonikis Papageorgiou

\section{Fotini Chatzigrigoriou}

General Hospital of Thessaloniki Papageorgiou: Geniko Nosokomeio Thessalonikis Papageorgiou

\section{Stella Karakatsani}

General Hospital of Thessaloniki Papageorgiou: Geniko Nosokomeio Thessalonikis Papageorgiou Ilias Chatziioannidis

Aristotle University of Thessaloniki School of Medicine: Aristoteleio Panepistemio Thessalonikes

Tmema latrikes

\section{Maria Tzitiridou}

University of Western Macedonia: Panepistemio Dytikes Makedonias

\section{Vassilis Aletras}

Panepistimio Makedonias: Panepistemio Makedonias

\section{Aikaterini Gotzamani}

Panepistimio Makedonias: Panepistemio Makedonias

\section{Research}


Keywords: breastfeeding, educational curriculum, healthcare professionals

Posted Date: July 7th, 2021

DOI: https://doi.org/10.21203/rs.3.rs-670495/v1

License: (c) (1) This work is licensed under a Creative Commons Attribution 4.0 International License. Read Full License 


\section{Abstract \\ Background}

To investigate the knowledge level, attitudes and perceptions of Gynecology healthcare professionals in Greece towards breastfeeding.

\section{Methods}

A self-administered questionnaire was provided asking to answer multiple choice questions. The study was conducted mainly at the facilities of Medical Faculty Aristotle University of Thessaloniki. The questionnaire was administered to 312 healthcare professionals (nurses, students, physicians and other healthcare professionals).

\section{Results}

Over $70 \%$ supported that their breastfeeding knowledge was moderate at best and could be further improved. $30 \%$ lacked knowledge concerning the management of special breastfeeding scenarios. $84 \%$ had previous personal breastfeeding experience or at least are willing to do so in the future (themselves or their partners) with $39.1 \%$ aiming to breastfeed approximately for one year. The same pattern was observed in terms of their breastfeeding recommendations to other mothers regardless of their sex. $59.6 \%$ admitted that they do not have the necessary time to properly inform mothers about breastfeeding while $72.4 \%$ acknowledged improper breastfeeding information as an important factor for the low breastfeeding rates in Greece. Finally, $80.4 \%$ stated that their education was lacking in didactic depth and their training in hands-on experience while $88.8 \%$ clearly underlined that there was definitely room for improvement in their education/training curriculum. Expert teams, well-organized educational programs and advanced computing could contribute to the personnel's harmonization with the various breastfeeding objectives to create a "breastfeeding-friendly" social environment.

\section{Conclusions}

This study revealed that although most Greek gynecology healthcare professionals have very positive attitudes towards breastfeeding, their breastfeeding knowledge was moderate at best and could be further improved.

\section{Background}

The term "Breastfeeding" is used to describe the process through which the baby receives any breast milk (1) and is considered to be highly important both for infants and their mothers for nutritional, immunologic, psychologic, and other health-related reasons. 
For the optimal health and development of infants, today WHO and UNICEF recommend that all infants should be exclusively breastfed for the first 6 months and continue to receive breast milk until 2 years of age to supplement other foods (2). In addition, the policy statement of American Academy of Pediatrics recognizes breastfeeding as the ideal form of infant nutrition, providing health benefits for both mothers and infants (3).

Studies in Greece have shown that during the decade 2007-2017 revealed a substantial improvement in all breastfeeding indicators. In 2017, most mothers initiated breast-feeding in the first $24 \mathrm{hrs}$ from birth, while rates of any breast-feeding remained above $50 \%$ by the end of the 4 th month (4). Increasing breastfeeding rates have been observed in other European countries as well during the same period, including among others, Scotland (5), France (6), Ireland (7), England (8) and Germany (9). However, it seems that despite the slight improvements that have been recorded in breastfeeding rates during the last decade, they continue to fall short of global recommendations, and many mothers, who initially chose to breastfeed, abandon breastfeeding because of the easy solution of formula-feeding (10).

Literature has shown that one of the most important determinants of the maternal decision to breastfeed is, apart from her knowledge and family attitudes, the support and involvement of healthcare professionals $(11-13)$. In fact, there is strong evidence suggesting that support from a trained healthcare professional can have a positive effect on initiation, duration and experiences of breastfeeding (14).

It is therefore important that nursing, medical and other students in other healthcare professions, acquire knowledge about breastfeeding, and develop skills to achieve effective support and appropriate care to pregnant women, and to new mothers with infants, towards breastfeeding (15). However, healthcare professionals do not always receive sufficient breastfeeding education during their foundational education program which makes them unable in effectively supporting mothers with breastfeeding (16, 17). A significant lack in breastfeeding knowledge among healthcare professionals can lead women to receive inappropriate and often conflicting information that may result in premature weaning and causation of breastfeeding (18-20).

Additionally, although the importance of knowledge has been underlined, knowledge about breastfeeding and its benefits alone is not enough for sufficient breastfeeding support; a positive attitude is also essential (21).

Few studies, to date, have investigated the nature of professionals' beliefs, instead relying on simple statements of support or agreement (22). The analysis of attitudes in much literature can be seen as being mainly descriptive without exploring the breadth and depth of health professionals' attitudes in this domain (23) and all those studies focused on healthcare professionals of different geographic regions (especially US and Europe) without, to our knowledge, any study analyzing the attitudes of Greek healthcare professionals towards this crucial and interesting objective.

Given these issues, it is important to investigate in a qualitative manner Greek healthcare professionals' views regarding breastfeeding, to obtain a clearer image of the depth, nature, and complexity of 
underlying attitudes. The aim of this study is to investigate the knowledge, attitudes and perceptions and education of Gynecology healthcare professionals in Greece associated with breastfeeding through the completion of a well-structured self-administered questionnaire asking the participating Greek healthcare professionals to answer multiple choice questions. Based on the findings of this study, the paper proposes potential strategies to improve the breastfeeding educational curriculum of Obstetrics and Gynecology Departments for a more "breastfeeding-friendly" social environment.

\section{Methods}

For the purpose of this study, a survey during 2019 was carried out, in which healthcare professionals including midwifes, midwife interns, physicians and others, were recruited to express their opinions about breastfeeding, its benefits, its principles and approaches. A well-structured self-administered questionnaire was provided to every participant asking to answer multiple choice questions.

After studying the available literature of former relative studies, a draft version of the study questionnaire was designed covering most of the important evaluating objectives of the study. Then, for the needs of the study, a designated team of healthcare professionals was formed to further improve the draft version of the questionnaire and develop its initial version during a preparative period in the second semester of 2018. During that preparative period, discussion with the form of informal communications during normal working hours was made concerning the nature of a hypothetical questionnaire, associated mainly with breastfeeding in Greece, which could be administered to working personnel asking for their opinions and attitudes towards the objectives of this study. More specifically, valuable information was exchanged from own working experience in Obstetrics and Gynecology Departments resulting in some important observations and recommendations, which were added to the draft questionnaire and the initial version was ready.

Before its administration, the initial questionnaire was pre-tested through a control group of healthcare professionals at a private Obstetrics and Gynecology Clinic with highly educated and skilled healthcare professionals completely aware of the breastfeeding and all its related objectives. The personnel of this hospital were asked to evaluate the comprehension level of the questionnaire and suggest possible modifications for better understanding. The comments from this "reviewing" group were evaluated and assessed leading at the end to some slight alternations made to a few questions for better clarity. This initial group of respondents was excluded from this study.

The final version of this anonymous self-administered questionnaire was distributed to working personnel though three different ways: a) during staff meetings in Hippokration General Hospital of Thessaloniki b) during academic activities in Thessaloniki Medical Faculty and c) during educational seminars where healthcare professionals from public and private sector in Greece participated. Before completing the questionnaire, each participant was asked to read and sign an informed consent form.

The introductory part of the questionnaire (6 questions) explored demographic characteristics of the respondents. In detail, participants were questioned about their age, educational level, profession, marital 
status, and numbers of offspring. The core part of the questionnaire consisted of three different thematical sections: the first one that was associated with their knowledge about breastfeeding (15 questions), the second one associated with their attitudes and perceptions towards breastfeeding (15 questions) and the last one with their education associated with breastfeeding (3 questions).

The questions were based on a Linkert scale where the respondents were asked to specify their level of agreement or disagreement on an agree-disagree scale for a series of statements addressed by the questions. The Linkert format was a typical five-level Likert item where: $1^{*}$ corresponded to "Strongly disagree" (St/Dis), 2* to "Somewhat Disagree" (Sm/Dis), $3^{*}$ to "Either agree or disagree" (Ag/Dis), 4* to "Somewhat Agree" (Sm/Ag) and 5* to "Strongly agree" (St/Ag).

The data obtained from the responses of the participants who answered the questionnaires were collected and analyzed with the help of the Statistical Package for the Social Sciences (SPSS) Version 24.0 (IBM).

\section{Results}

\section{Sample Characteristics and Demographics}

The questionnaire was administered to a total of 344 healthcare professionals. From this initial group of 344 participants, a total of 312 agreed to answer ( $90.7 \%$ response rate) the questionnaire of the study. This group of 312 respondents mainly consisted of nurses and students (nursing or medical ones). In detail, the final study group included 112 nurses, 134 students, 57 physicians and 9 other healthcare professionals working in gynecological departments of public or private sector in Greece with the vast majority being women (274 out of 312 ) (Table 1 ). 
Table 1

Demographic characteristics of participants.

\begin{tabular}{|c|c|c|}
\hline Demographics & $\%$ & $\mathrm{n}=\mathbf{3 1 2}$ \\
\hline \multicolumn{3}{|l|}{ Sex } \\
\hline Male & 12.2 & 38 \\
\hline Female & 87.8 & 274 \\
\hline \multicolumn{3}{|l|}{ Age (years) } \\
\hline$<20$ & 14.4 & 45 \\
\hline $20-29$ & 45.2 & 141 \\
\hline $30-39$ & 18.2 & 57 \\
\hline $40-49$ & 12.2 & 38 \\
\hline $50-59$ & 10.0 & 31 \\
\hline \multicolumn{3}{|l|}{ Educational level } \\
\hline Technological Educational Institute & 78.2 & 244 \\
\hline University & 14.7 & 46 \\
\hline Post-Graduate (MSc / PhD) & 7.1 & 22 \\
\hline \multicolumn{3}{|l|}{ Profession } \\
\hline Nurse & 35.9 & 112 \\
\hline Student (nursing / medical) & 42.9 & 134 \\
\hline Physician & 18.3 & 57 \\
\hline Other & 2.9 & 9 \\
\hline \multicolumn{3}{|l|}{ Marital status } \\
\hline Single & 61.5 & 192 \\
\hline Married & 38.5 & 120 \\
\hline \multicolumn{3}{|l|}{ Number of children } \\
\hline 0 & 67.0 & 209 \\
\hline 1 & 10.9 & 34 \\
\hline 2 & 18.2 & 57 \\
\hline 3 & 2.9 & 9 \\
\hline$>3$ & 1.0 & 3 \\
\hline
\end{tabular}


Regarding the age of the study group, more than half of the respondents (59.6\%) were at most in their early twenties followed by a $30.4 \%$ of them being between 30 and 50 years old and a mere $10 \%$ were older than 50 years old. Because of the relative low average age, more than $60 \%$ of the participants were single and without any children (192 and 209 out of 312 respectively) while only $38.5 \%$ were married and $33 \%$ had families of at least one child. Regarding educational level and status, 244 out of 312 had attended or were attending a Nursing Technical Institute (78.2\%), 46 had attended or were attending a University Department (2.6\%) and 22 had obtained a higher educational post-graduate status (MSc or $\mathrm{PhD})(7.1 \%)$.

\section{Knowledge, attitudes and perceptions of healthcare professionals in Greece towards breastfeeding:}

Table 2 presents the questions that were asked to respondents with the form of an anonymous selfadministered questionnaire along with the received answers in the three thematical subsections: a) knowledge about breastfeeding $b$ ) attitudes and perceptions towards breastfeeding and c) education associated with breastfeeding. 
Table 2

Evaluating the knowledge, attitudes and perceptions of healthcare professionals in Greece towards breastfeeding.

\begin{tabular}{|c|c|c|c|c|c|}
\hline $\begin{array}{l}\text { KNOWLEDGE ABOUT } \\
\text { BREASTFEEDING }\end{array}$ & $\begin{array}{l}\text { 1* } \\
\text { (St/Dis) }\end{array}$ & $\begin{array}{l}2^{*} \\
\text { (Sm/Dis) }\end{array}$ & $\begin{array}{l}3^{*} \\
\text { (Ag/Dis) }\end{array}$ & $\begin{array}{l}4^{*} \\
(\mathrm{Sm} / \mathrm{Ag})\end{array}$ & $\begin{array}{l}5^{*} \\
(\mathrm{St} / \mathrm{Ag})\end{array}$ \\
\hline $\begin{array}{l}\text { Are you confident with your } \\
\text { knowledge about breastfeeding? }\end{array}$ & $\begin{array}{l}49 \\
(15.7 \%)\end{array}$ & $53(17 \%)$ & $\begin{array}{l}157 \\
(50.3 \%)\end{array}$ & $\begin{array}{l}28 \\
(8.9 \%)\end{array}$ & $\begin{array}{l}25 \\
(8.1 \%)\end{array}$ \\
\hline $\begin{array}{l}\text { Have you obtained most of your } \\
\text { knowledge about breastfeeding } \\
\text { through your own personal research? }\end{array}$ & $\begin{array}{l}12 \\
(3.6 \%)\end{array}$ & $\begin{array}{l}20 \\
(6.4 \%)\end{array}$ & $\begin{array}{l}48 \\
(15.5 \%)\end{array}$ & $\begin{array}{l}89 \\
(28.6 \%)\end{array}$ & $\begin{array}{l}143 \\
(45.9 \%)\end{array}$ \\
\hline $\begin{array}{l}\text { Could your level of knowledge be } \\
\text { improved? }\end{array}$ & $\begin{array}{l}9 \\
(2.9 \%)\end{array}$ & $\begin{array}{l}8 \\
(2.6 \%)\end{array}$ & $\begin{array}{l}38 \\
(12.2 \%)\end{array}$ & $\begin{array}{l}95 \\
(30.4 \%)\end{array}$ & $\begin{array}{l}162 \\
(51.9 \%)\end{array}$ \\
\hline $\begin{array}{l}\text { Are you confident concerning the } \\
\text { management of any breastfeeding } \\
\text { related issues in your everyday } \\
\text { practice? }\end{array}$ & $\begin{array}{l}12 \\
(3.6 \%)\end{array}$ & $\begin{array}{l}52 \\
(16.6 \%)\end{array}$ & $\begin{array}{l}98 \\
(31.5 \%)\end{array}$ & $\begin{array}{l}102 \\
(32.8 \%)\end{array}$ & $\begin{array}{l}48 \\
(15.5 \%)\end{array}$ \\
\hline $\begin{array}{l}\text { Is breastfed milk the ideal meal for an } \\
\text { infant? }\end{array}$ & $\begin{array}{l}0 \\
(0 \%)\end{array}$ & $\begin{array}{l}2 \\
(0.7 \%)\end{array}$ & $\begin{array}{l}15 \\
(4.8 \%)\end{array}$ & $\begin{array}{l}54 \\
(17.2 \%)\end{array}$ & $\begin{array}{l}241 \\
(77.3 \%)\end{array}$ \\
\hline $\begin{array}{l}\text { Are ready meals (formulas) as } \\
\text { nutritious as the maternal milk? }\end{array}$ & $\begin{array}{l}22 \\
(7.1 \%)\end{array}$ & $\begin{array}{l}33 \\
(10.6 \%)\end{array}$ & $\begin{array}{l}65 \\
(20.8 \%)\end{array}$ & $\begin{array}{l}124 \\
(39.7 \%)\end{array}$ & $\begin{array}{l}68 \\
(21.8 \%)\end{array}$ \\
\hline $\begin{array}{l}\text { Are formulas easier to digest than } \\
\text { maternal milk? }\end{array}$ & $\begin{array}{l}64 \\
(20.5 \%)\end{array}$ & $\begin{array}{l}68 \\
(21.8 \%)\end{array}$ & $\begin{array}{l}79 \\
(25.3 \%)\end{array}$ & $\begin{array}{l}52 \\
(16.7 \%)\end{array}$ & $\begin{array}{l}49 \\
(15.7 \%)\end{array}$ \\
\hline $\begin{array}{l}\text { Should a mother/casual drinker avoid } \\
\text { breastfeeding? }\end{array}$ & $\begin{array}{l}27 \\
(8.6 \%)\end{array}$ & $\begin{array}{l}52 \\
(16.7 \%)\end{array}$ & $\begin{array}{l}88 \\
(28.2 \%)\end{array}$ & $\begin{array}{l}64 \\
(20.5 \%)\end{array}$ & $\begin{array}{l}81 \\
(26 \%)\end{array}$ \\
\hline $\begin{array}{l}\text { Can a mother/carrier of Hepatitis B } \\
\text { that has been vaccinated, safely } \\
\text { breastfeed her baby? }\end{array}$ & $\begin{array}{l}58 \\
(18.6 \%)\end{array}$ & $\begin{array}{l}71 \\
(22.7 \%)\end{array}$ & $\begin{array}{l}84 \\
(26.9 \%)\end{array}$ & $\begin{array}{l}50 \\
(16.1 \%)\end{array}$ & $\begin{array}{l}49 \\
(15.7 \%)\end{array}$ \\
\hline $\begin{array}{l}\text { Can a mother/carrier of HIV transfer } \\
\text { the virus to her baby through } \\
\text { breastfeeding? }\end{array}$ & $\begin{array}{l}67 \\
(21.5 \%)\end{array}$ & $\begin{array}{l}54 \\
(17.3 \%)\end{array}$ & $\begin{array}{l}91 \\
(29.2 \%)\end{array}$ & $\begin{array}{l}64 \\
(20.5 \%)\end{array}$ & $\begin{array}{l}36 \\
(11.5 \%)\end{array}$ \\
\hline $\begin{array}{l}\text { Should a mother with fever }>38^{\circ} \mathrm{C} \\
\text { interrupt breastfeeding temporarily? }\end{array}$ & $\begin{array}{l}47 \\
(15.1 \%)\end{array}$ & $\begin{array}{l}45 \\
(14.4 \%)\end{array}$ & $\begin{array}{l}84 \\
(26.9 \%)\end{array}$ & $\begin{array}{l}64 \\
(20.5 \%)\end{array}$ & $\begin{array}{l}72 \\
(23.1 \%)\end{array}$ \\
\hline $\begin{array}{l}\text { In case of mastitis, should a mother } \\
\text { stop breastfeeding? }\end{array}$ & $\begin{array}{l}51 \\
(16.4 \%)\end{array}$ & $\begin{array}{l}49 \\
(15.7 \%)\end{array}$ & $\begin{array}{l}69 \\
(22.1 \%)\end{array}$ & $\begin{array}{l}72 \\
(23.1 \%)\end{array}$ & $\begin{array}{l}71 \\
(22.7 \%)\end{array}$ \\
\hline
\end{tabular}




\begin{tabular}{|c|c|c|c|c|c|}
\hline \multirow{2}{*}{$\begin{array}{l}\text { Should mothers/ regular smokers be } \\
\text { encouraged to stop breastfeeding? }\end{array}$} & 47 & 71 & 79 & 56 & 58 \\
\hline & (15.1\%) & $(22.8 \%)$ & (25.4\%) & $(18 \%)$ & (18.7\%) \\
\hline \multirow{2}{*}{$\begin{array}{l}\text { Can a mother make safe use of } \\
\text { medication in breastfeeding? }\end{array}$} & 74 & 78 & 79 & 52 & 29 \\
\hline & (23.7\%) & $(25 \%)$ & $(25.3 \%)$ & (16.7\%) & $(9.3 \%)$ \\
\hline \multirow{2}{*}{$\begin{array}{l}\text { Do breast plastic surgeries make } \\
\text { breastfeeding difficult? }\end{array}$} & 62 & 67 & 81 & 71 & 31 \\
\hline & (19.9\%) & $(21.5 \%)$ & (25.9\%) & (22.8\%) & (9.9\%) \\
\hline \multirow{2}{*}{$\begin{array}{l}\text { ATTITUDES AND PERCEPTIONS } \\
\text { TOWARDS BREASTFEEDING }\end{array}$} & $1 *$ & $2^{*}$ & $3^{*}$ & $4^{*}$ & $5^{*}$ \\
\hline & (St/Dis) & (Sm/Dis) & (Ag/Dis) & $(\mathrm{Sm} / \mathrm{Ag})$ & (St/Ag) \\
\hline \multirow{2}{*}{$\begin{array}{l}\text { Have you breastfed your children or } \\
\text { do you intend to do so in the future } \\
\text { (yourselves or your partners)? }\end{array}$} & 11 & 21 & 18 & 89 & 173 \\
\hline & $(3.5 \%)$ & $(6.7 \%)$ & $(5.8 \%)$ & $(28.5 \%)$ & (55.5\%) \\
\hline \multirow{3}{*}{$\begin{array}{l}\text { For how long have you breastfed your } \\
\text { children or do you intend to do so in } \\
\text { the future (yourselves or your } \\
\text { partners)? }\end{array}$} & 1month & 3months & 6 months & 12 months & 24months \\
\hline & 2 & 8 & 88 & 122 & 92 \\
\hline & $(0.7 \%)$ & $(2.8 \%)$ & $(28 \%)$ & (39.1\%) & $(29.5 \%)$ \\
\hline \multirow{2}{*}{$\begin{array}{l}\text { Do you recommend breastfeeding to } \\
\text { mothers? }\end{array}$} & 5 & 6 & 31 & 81 & 189 \\
\hline & $(1.6 \%)$ & $(1.9 \%)$ & $(9.9 \%)$ & $(26 \%)$ & $(60.6 \%)$ \\
\hline \multirow{3}{*}{$\begin{array}{l}\text { For how long would you recommend } \\
\text { breastfeeding? }\end{array}$} & 1month & 3months & 6months & 12 months & 24months \\
\hline & 2 & 6 & 64 & 156 & 84 \\
\hline & $(0.7 \%)$ & $(1.9 \%)$ & $(20.5 \%)$ & $(50 \%)$ & $(26.9 \%)$ \\
\hline \multirow{2}{*}{$\begin{array}{l}\text { Are you in favour of exclusive } \\
\text { breastfeeding? }\end{array}$} & 3 & 2 & 69 & 74 & 164 \\
\hline & $(1 \%)$ & $(0.7 \%)$ & $22.1 \%)$ & (23.7\%) & $(52.5 \%)$ \\
\hline \multirow{2}{*}{$\begin{array}{l}\text { Are you in favour of breastfeeding } \\
\text { combined with formulas? }\end{array}$} & 94 & 65 & 45 & 50 & 58 \\
\hline & $(30.2 \%)$ & (20.8\%) & (14.4\%) & $(16 \%)$ & (18.6\%) \\
\hline \multirow{2}{*}{$\begin{array}{l}\text { Are you in favour of public } \\
\text { breastfeeding? }\end{array}$} & 5 & 6 & 26 & 91 & 184 \\
\hline & $(1.6 \%)$ & $(1.9 \%)$ & $(8.3 \%)$ & $(29.2 \%)$ & (59\%) \\
\hline \multirow{2}{*}{$\begin{array}{l}\text { Are you in favour of breastfeeding } \\
\text { while returning to work? }\end{array}$} & 7 & 9 & 23 & 97 & 176 \\
\hline & $(2.2 \%)$ & $(2.9 \%)$ & $(7.4 \%)$ & $(31 \%)$ & $(56.5 \%)$ \\
\hline \multirow{2}{*}{$\begin{array}{l}\text { Is breastfeeding an obstacle for the } \\
\text { social and professional obligations of } \\
\text { mothers? }\end{array}$} & 17 & 18 & 58 & 71 & 148 \\
\hline & $(5.4 \%)$ & $(5.7 \%)$ & (18.6\%) & $(22.8 \%)$ & $(47.5 \%)$ \\
\hline
\end{tabular}




\begin{tabular}{|c|c|c|c|c|c|}
\hline \multicolumn{6}{|l|}{$n=312$} \\
\hline \multirow{2}{*}{$\begin{array}{l}\text { Does breastfeeding make the father } \\
\text { feel isolated from raising of his child? }\end{array}$} & 19 & 15 & 38 & 89 & 151 \\
\hline & $(6.1 \%)$ & $(4.8 \%)$ & (12.2\%) & $(28.5 \%)$ & (48.4\%) \\
\hline \multirow{2}{*}{$\begin{array}{l}\text { Is breastfeeding better than formulas } \\
\text { in the promotion of bonding between } \\
\text { the mother and her baby? }\end{array}$} & 2 & 2 & 27 & 92 & 189 \\
\hline & $(0.7 \%)$ & (0.7\%) & $(8.6 \%)$ & $(29.5 \%)$ & (60.5\%) \\
\hline \multirow{2}{*}{$\begin{array}{l}\text { Is breastfeeding more convenient and } \\
\text { cheaper than formulas? }\end{array}$} & 11 & 21 & 18 & 89 & 173 \\
\hline & $(3.5 \%)$ & (6.7\%) & $(5.7 \%)$ & $(28.6 \%)$ & (55.5\%) \\
\hline \multirow{2}{*}{$\begin{array}{l}\text { Should mothers with excess of milk } \\
\text { be encouraged to donate their milk to } \\
\text { maternal milk banks? }\end{array}$} & 15 & 17 & 24 & 94 & 162 \\
\hline & $(3.5 \%)$ & $(6.7 \%)$ & $(5.7 \%)$ & $(28.6 \%)$ & (55.5\%) \\
\hline \multirow{2}{*}{$\begin{array}{l}\text { Do you have the time to properly } \\
\text { inform the mothers about the benefits } \\
\text { of breastfeeding? }\end{array}$} & 101 & 85 & 61 & 42 & 23 \\
\hline & $(32.6 \%)$ & $(27.1 \%)$ & (19.5\%) & (13.5\%) & $(7.3 \%)$ \\
\hline \multirow{2}{*}{$\begin{array}{l}\text { Are the low breastfeeding rates in } \\
\text { Greece associated, to an important } \\
\text { degree, with the fact that healthcare } \\
\text { professionals do not properly inform } \\
\text { mothers about breastfeeding? }\end{array}$} & 25 & 27 & 34 & 84 & 142 \\
\hline & $(8 \%)$ & $(8.6 \%)$ & $(10.9 \%)$ & $(27 \%)$ & $(45.5 \%)$ \\
\hline \multirow[t]{2}{*}{$\begin{array}{l}\text { BREASTFEEDING EDUCATION \& } \\
\text { TRAINING }\end{array}$} & $1 *$ & $2^{*}$ & $3^{*}$ & $4^{*}$ & $5^{*}$ \\
\hline & (St/Dis) & (Sm/Dis) & (Ag/Dis) & (Sm/Ag) & (St/Ag) \\
\hline \multirow{2}{*}{$\begin{array}{l}\text { Was the education and training you } \\
\text { received from your department } \\
\text { detailed and accurate? }\end{array}$} & 107 & 117 & 57 & 18 & 13 \\
\hline & $(34.4 \%)$ & $(37.5 \%)$ & (18.3\%) & $(5.7 \%)$ & $(4.1 \%)$ \\
\hline \multirow{2}{*}{$\begin{array}{l}\text { Did the education and training you } \\
\text { received from your department lack in } \\
\text { didactic depth and hands-on } \\
\text { experience? }\end{array}$} & 11 & 16 & 34 & 86 & 165 \\
\hline & (3.5\%) & $(5.1 \%)$ & $(10.9 \%)$ & $(27.6 \%)$ & (52.9\%) \\
\hline \multirow{2}{*}{$\begin{array}{l}\text { Could your education and training } \\
\text { provided from your department have } \\
\text { been of higher quality? }\end{array}$} & 11 & 11 & 13 & 96 & 181 \\
\hline & $(3.5 \%)$ & $(3.5 \%)$ & $(4.2 \%)$ & (30.8\%) & $(58 \%)$ \\
\hline
\end{tabular}

The evaluation of the first thematical section revealed that half of the participants (50.3\%) characterized their self-confidence in terms of their knowledge about breastfeeding as moderate while less than one third $(32.7 \%)$ was not confident at all and only $17 \%$ were highly confident. 232 out of 312 respondents (74.5\%) reported that that they had hardly received any formal breastfeeding training from their department or school and admitted that their current level of knowledge has been achieved almost entirely by their own personal research and everyday working experience while over $80 \%$ of them supported that there was definitely room for improvement in terms of their breastfeeding knowledge. To this direction, for every 10 healthcare professionals who completed the questionnaire, at least 3 of them 
lacked knowledge concerning the management of special breastfeeding scenarios such as mastitis development, Hepatitis B or HIV status, high fever appearance or safe use of medication from the breastfeeding mothers. However, despite admitting their low knowledge levels, almost half of the participants $(n=150,48.3 \%$ ) stated that they were very confident concerning the management of any breastfeeding related issues in their everyday practice. As expected, the vast majority were of the opinion that breastfed milk is the ideal meal for an infant while being more nutritious than ready meals (formulas) (94.5\% and $61.5 \%$ respectively).

The evaluation of the second thematical section revealed that most participants had previous personal breastfeeding experience or at least are willing to do so in the future (themselves or their partners) (262 out of 312 respondents) with most of them aiming to breastfeed approximately for one year $(39.1 \%)$ followed by those either willing to extend breastfeeding up to 2 years or reduce it down to 6 months ( $29.5 \%$ and $28 \%$ respectively). The same pattern was observed in terms of their recommendation of breastfeeding to other mothers with 270 out of 312 Greek healthcare professionals being supportive of breastfeeding up to 1 year (50\%) with a balance between the supporters of either 6 months or 24 months (26.9\% and $20.5 \%$ respectively). Most of them strongly supported the option of exclusive breastfeeding (76.2\%) and showed their disagreement over a potential combination of breastfeeding and formulas (75.4\%). Moreover, the vast majority was in favor of public breastfeeding (88.2\%) and breastfeeding while returning to work (87.5\%) despite the fact they considered that breastfeeding could become an obstacle for the social and professional obligations of mothers (70.3\%). In terms of bonding, it was widely believed that breastfeeding is better than formulas for creating a strong emotional bond between the baby and the mother while at the same time it is highly likely that the process may isolate the father from the bonding process ( $90 \%$ and $76.9 \%$ respectively). 262 out of the 312 participants underlined the superiority of breastfeeding over formula-feeding in terms of convenience and cost. Also, a clear support over donation of maternal milk was reported from over $80 \%$ of the participants. Finally, most healthcare professionals (186 out of 312 participants) admitted that they do not have the necessary time to properly inform the mothers about the benefits of breastfeeding while at the same time most of them (226 out of 312 participants) acknowledged their improper breastfeeding informing as an important contributing factor for the low breastfeeding rates among Greek mothers.

The evaluation of the last thematical section showed that most participants basically had not received any breastfeeding education/training from their departments or that their education/training was superficial as reported from the $71.9 \%$ of the participants. In fact, 251 out of 312 participants stated that although having been taught the basic principles and theoretical background associated with breastfeeding from their departments, their education was lacking in didactic depth and their training in hands-on experience while the vast majority (88.8\%) clearly underlined that there was definitely room for improvement in their education/training curriculum.

\section{Discussion}


The aim of this study was to investigate the knowledge level, attitudes and perceptions of Gynecology healthcare professionals in Greece towards breastfeeding with a questionnaire focusing especially on various relative objectives. In fact, this study of the knowledge, attitudes and practices of established Greek healthcare professionals in relation to breastfeeding, by evaluating: their knowledge, their attitudes and perceptions and their education regarding breastfeeding.

In terms of the first theme, most participants supported that their level of knowledge about breastfeeding was moderate at best and could be further improved. Many of them reported that they had hardly received any formal breastfeeding training from their department or school and admitted that their current level of knowledge has been achieved almost entirely by their own personal research and everyday working experience. These findings are on agreement with various studies in other countries where healthcare professionals admitted that they were significant knowledge gaps in their background which made them ill-prepared to counsel breast-feeding mothers (24-30). Most participants lacked knowledge about the safe use of medication from mothers during breastfeeding, something that has been reported by Amir et for Australian healthcare professionals as well (31). Additionally, a significant number lacked knowledge concerning the management of special breastfeeding scenarios such as mastitis development, Hepatitis B or HIV status or high fever appearance, a finding that has also been reported by Brodribb et al for Australian healthcare professionals (32).

However, despite admitting their low knowledge levels, most of the participants stated that they were very confident concerning the management of any breastfeeding related issues in their everyday practice. This high level of confidence was in contrast to other studies where healthcare professionals wondered whether their lack of breastfeeding knowledge could have a negative impact on their ability to handle effectively any breastfeeding related issues (32). This difference could possibly be explained by the fact that most participants in this study were of relative low age. Their age-related enthusiasm and energy combined with their lack of working experience could result in higher levels of confidence compared to those of experienced fully qualified older healthcare professionals that participated in other studies (24$29,32)$. In fact, Ahmed et al found that despite Egyptian healthcare students having low knowledge scores and not holding strongly positive attitudes towards breastfeeding, more than $70 \%$ of the students indicated they were confident or very confident about their ability to support breastfeeding (33).

In terms of their attitudes and perceptions regarding breastfeeding, most participants generally supported breastfeeding up to 1 year of age followed by those supporting the breastfeeding up to 2 years of age. Furthermore, the vast majority was in favor of public breastfeeding and breastfeeding while returning to work. The same picture has been painted by previous studies evaluating healthcare professionals from other countries around the globe including United States, Mexico, United Kingdom (Ireland, Scotland, England), Iraq, Israel, Taiwan and Australia which revealed very positive attitudes towards breastfeeding $(26-30,34,35)$, although one study found that over one third of nursing American students were against public breastfeeding and another reported that all students held this belief $(36,37)$. 
In terms of their education regarding breastfeeding, most participants admitted that basically they have not received any breastfeeding education/training by their departments, or that their education/training was superficial. This was in agreement with Freed et al who reported that only $38 \%$ had received any education from their departments about breastfeeding and indicated what little they knew came from other residents and nurses (38). In fact, most participants in this study stated that although having learned basic principles about breastfeeding from their departments, their education was lacking in didactic depth and their training in hands-on experience and that there was definitely room for improvement in their education/training curriculum. This is very much in line with other studies, where healthcare professionals stated that their education and training about breastfeeding was more of superficial instead of being substantial either in theoretical background or technical skills $(35,39)$.

It has been found that breastfeeding education for healthcare professionals results in greater knowledge, improved use of resources, and a more proactive approach to breastfeeding support and the creation of a breastfeeding-friendly environment $(40,41)$. A subsequent study confirmed that healthcare professionals' knowledge was low and their misinformation disturbingly high making the need for the design of educational \& training programs that would provide comprehensive education on breastfeeding (42). Another study revealed a reported low level of confidence in their skills underlying the need for the need for didactic and clinical training in breastfeeding (34).

This study also revealed that healthcare professionals that have previous breastfeeding experience (themselves or their partners) or are willing to breastfeed their newborns are most likely to recommend breastfeeding to other mothers, a finding in agreement with previous studies where it was shown that healthcare professionals with breastfeeding experience had more positive attitudes towards breastfeeding than those without any personal experience $(27,43-45)$. Also, this study revealed that the vast majority considered that breastfeeding was more convenient and cheaper than formulas whereas in other former studies there was a balance between the convenience of both feeding methods (46). Moreover, it was shown that most healthcare professionals agreed that breastfeeding is far more superior to formula feeding in promoting bonding between the mother and her baby matching the opinion of healthcare professionals from other studies $(30,46,47)$. Regarding bonding between the father and his baby, a significant number of the participants (both male and female) stated that the breastfeeding excludes the father from the raising of his child since it basically involves only the mother of the child. This is a finding for which the literature is inconclusive since there are studies that have raised concerns whether breastfeeding might make fathers feel excluded (30) whereas there are other ones where most healthcare professionals (either male or female) totally agree that breastfeeding does not affect the bonding process between the father and his baby (46).

The above results are very interesting and they can assist in developing breastfeeding policies and professional education to support Greek healthcare professionals in this vital role.

It is a well-established fact that breastfeeding is important to infants and their mothers for nutritional, immunologic, psychologic, and other health reasons is an established fact. While all the participating 
healthcare professionals had positive attitudes towards breastfeeding, they were often lacking in knowledge and training to provide strong support to mothers during their breastfeeding journey. To solve this educational problem, the existing educational curriculum should be improved since as stated by the participants there is definitely room for improvement. To establish breastfeeding and human lactation as an integral part of medical student education, the topic should be included in the present curriculum at the appropriate natural points, whether it is a class on anatomy, physiology, nutrition, endocrinology, women's health, or infant care, discussing topics such as the properties of breast milk, benefits of breastfeeding for both mother and infant, assessment parameters for effective breastfeeding, maternal support, and achievement of proper latch in a didactic instructional manner $(16,33,37,48)$.

A range of formats and educational strategies can be applied including, apart from the didactic lecture style, simulation and clinical placement, evidence-based seminar updates (49) with case studies (50) in conjunction with, or perhaps replacing, didactic classroom lectures. Specialized training workshops and seminars have been characterized as useful as well (48-50). Increasingly online education can be applied as well. In fact, studies have shown that the additional online module improved undergraduate nursing students' learning as well as their confidence in the clinical setting (51).

The program should be taught by healthcare professionals who are qualified faculty members recognized by their colleagues and certified by specialty examining boards. The classes should be part of the total curriculum and not something a student can elect to do only in the last year of the program, when most of the assignments are by electives since it is highly unlikely that graduate physicians or nurses in practice will attend a teaching day exclusively on breastfeeding which may not serve their educational needs when they are also responsible for keeping up to date on the constant flow of advancements in every field of Modern Medicine. However, what needs to be established here is that much remains to be learned in Modern Medicine, and lactation should be part of it (42).

Practical experience should be provided through clinical placement at a hospital based maternity unit where nursing and medical students can have opportunities to observe and interact with lactation consultants, nurses and other healthcare professionals as they provided breastfeeding support to new mothers $(16,33,37,52)$. Providing students with opportunities to practice breastfeeding management skills before actually caring for clients in a clinical setting may increase confidence (33).

The ideal educational curriculum should ensure that all participating healthcare professionals will receive accurate breastfeeding education including both the knowledge and skills to support women to breastfeed (53-55). For facility personnel whose role may involve educating, advising or assisting women in relation to breastfeeding, they should have a minimum of 20 hours of breastfeeding education, consisting of at least 8 hours theoretical education and at least 3 hours relevant supervised clinical experience on breastfeeding (53-55). The education program may include various delivery options such as workshops, face-to-face or online education (Yang et al., 2018). Two intervention studies were based on the BFHI $20 \mathrm{hr}$ module but both adapted this by either reducing the content to $16 \mathrm{~h}$ online (56) or 
reducing to $10 \mathrm{~h}$ with a significant clinical component of 8 weeks (57). Both had positive effects on students' breastfeeding knowledge.

Hospital administrative, medical, nursing, and nutrition staff should establish a strategy that promotes and supports breastfeeding through the formation of an interdisciplinary team responsible for the implementation of hospital policies and provision of ongoing educational activities. There is a need for training which can specifically address feelings of hopelessness and powerlessness in staff with regards the positive impact they can have on breastfeeding behavior, and for policy makers to acknowledge and address the ambivalence that exists regarding some current promotion practices (23).

Breastfeeding topics should become part of a well-rounded continuing education program that includes a number of other important issues, such as infectious diseases, endocrine problems, growth, development, and perinatology. When breastfeeding is included in programs on infant nutrition and presented by a certified healthcare professional, it will gain the status it needs.

Expert teams, well-organized educational programs and advanced computing could contribute to the personnel's harmonization with the various breastfeeding objectives in order to create a "breastfeedingfriendly" social environment.

\section{Conclusions}

This study revealed that despite their very positive attitudes towards breastfeeding, the level of breastfeeding knowledge of most Greek gynecology healthcare professionals, was moderate at best and could be further improved. They had hardly ever received any formal breastfeeding training by their departments, while lacking knowledge concerned mainly the management of special breastfeeding scenarios. Most of the participating healthcare professionals stated that their education and training about breastfeeding was more of superficial instead of being substantial either in theoretical background or technical skills making the improvement of current educational breastfeeding curriculum in the Obstetrics and Gynecology Departments an urgent necessity.

This study has two important limitations. The first one is associated with the self-reported nature of the questionnaire, since in case of potential misunderstanding of the questions from the participants, they might be reluctant to request relative elucidations when answering the questionnaire. The second one is associated with the demographics of the participants. More specifically, 246 out of 312 participants were either professional nurses or students (nursing or medical ones). This makes it difficult to generalize the results and extract conclusions about the opinions and attitudes of other healthcare professionals (gynecologists, lactation specialists, pediatricians etc.). Also, the relatively young average age of the participants (134 out of 312 were students) could be considered as another limitation. Furthermore, this study included a sample group consisting mainly from Greek healthcare professionals from a limited geographical area (Thessaloniki, Greece) and as an outcome it is possible that our findings may not reflect exactly the entire Greek residence. However, it includes a significant number of individuals and the reported findings can cast light on the so far unknown area of breastfeeding knowledge, attitudes and 
practices of Greek healthcare professionals and provide new and useful insights. Future studies could target a larger number of respondents focusing on a more balanced composition of the responding subgroups that should include if possible equal numbers of all the working personnel employed in Gynecology Departments as well as heads of medical and nursing services, while at the same time trying to achieve a wider variety in the respondents' age and working experience, in order to extrapolate more universal results.

The results of this study are of high importance and could possibly assist in designing and implementing more efficient breastfeeding educational curriculums to support Greek healthcare professionals in their effort to support mothers during their breastfeeding journey.

\section{Declarations}

Ethics approval and consent to participate: Before participation, each participant was asked to read and sign an informed consent form.

Consent for publication: Not applicable.

Availability of data and materials: The data that support the findings of this study are available from $\mathrm{Dr}$ E. Vavoulidis but restrictions apply to the availability of these data, which were used under license for the current study, and so are not publicly available. Data are however available from the authors upon reasonable request and with permission of DrE. Vavoulidis.

Competing interests: The authors declare that they have no competing interests.

Funding: Not applicable.

Authors' contributions: TT, EVa and KD contributed to the conception and design of the study; TT, EVa, ES, $\mathrm{EVo}, \mathrm{SI}, \mathrm{FC}$, SK to the acquisition, analysis and interpretation of data; TT, Eva, KD, IC, MT, VA, AG have drafted the work and substantively revised it. All participating authors have reviewed the document carefully prior to submission, have approved the submitted version and have agreed to be personally accountable for their own contributions.

Acknowledgements: We would like to personally thank the entire hospital personnel and all the healthcare professionals for their participation in this study.

\section{References}

1. World Health Organization. Indicators for assessing infant and young child feeding practices [Internet]. Geneva, Switzerland; 2007. Available from: .

2. WHO. WHO | Global strategy for infant and young child feeding. WHO [Internet]. 2017 [cited 2020 Dec 26]; Available from: http://www.who.int/nutrition/publications/infantfeeding/9241562218/en/. 
3. Gartner L, Morton J, Lawrence R, Naylor A, O'Hare D, Schanler R, et al. Breastfeeding and the use of human milk [Internet]. Vol. 115, Pediatrics. Pediatrics; 2005 [cited 2020 Dec 23]. p. 496-506.

Available from: https://pubmed.ncbi.nlm.nih.gov/15687461/.

4. Iliodromiti Z, Zografaki I, Papamichail D, Stavrou T, Gaki E, Ekizoglou C, et al. Increase of breastfeeding in the past decade in Greece, but still low uptake: Cross-sectional studies in 2007 and 2017. Public Health Nutr [Internet]. 2020 Apr 1 [cited 2021 Jan 3];23(6):961-70. Available from: https://www.cambridge.org/core/journals/public-health-nutrition/article/abs/increase-ofbreastfeeding-in-the-past-decade-in-greece-but-still-low-uptake-crosssectional-studies-in-2007-and2017/BD992B5DF2A943DA085BC6E64573681C.

5. Skafida V. Change in breastfeeding patterns in Scotland between 2004 and 2011 and the role of health policy. Eur J Public Health [Internet]. 2014 Dec 1 [cited 2021 Jan 3];24(6):1033-41. Available from: https://pubmed.ncbi.nlm.nih.gov/24642601/.

6. Bonet M, Kaminski M, Blondel B. Differential trends in breastfeeding according to maternal and hospital characteristics: Results from the French National Perinatal Surveys. Acta Paediatr Int J Paediatr [Internet]. 2007 Sep [cited 2021 Jan 3];96(9):1290-5. Available from: https://pubmed.ncbi.nlm.nih.gov/17666102/.

7. Brick A, Nolan A. Explaining the increase in breastfeeding at hospital discharge in Ireland, 20042010. Ir J Med Sci [Internet]. 2014 Sep 8 [cited 2021 Jan 3];183(3):333-9. Available from: https://link.springer.com/article/10.1007/s11845-013-1012-0.

8. Oakley LL, Kurinczuk JJ, Renfrew MJ, Quigley MA. Breastfeeding in England: time trends 2005-2006 to 2012-2013 and inequalities by area profile. Matern Child Nutr [Internet]. 2016 Jul 1 [cited 2021 Jan 3];12(3):440-51. Available from: https://pubmed.ncbi.nlm.nih.gov/25422164/.

9. Libuda L, Bolzenius K, Alexy U. Breastfeeding trends in healthy infants since 1990 - results of the DONALD study. Eur J Clin Nutr [Internet]. 2017 Aug 1 [cited 2021 Jan 3];71(8):1016-8. Available from: https://pubmed.ncbi.nlm.nih.gov/28656969/.

10. Tavoulari E-F, Benetou V, Vlastarakos PV, Psaltopoulou T, Chrousos G, Kreatsas G, et al. Factors affecting breastfeeding duration in Greece: What is important? World J Clin Pediatr [Internet]. 2016 [cited 2021 Jan 3];5(3):349. Available from: /pmc/articles/PMC4978630/?report = abstract.

11. Bai YK, Middlestadt SE, Peng CYJ, Fly AD. Psychosocial factors underlying the mother's decision to continue exclusive breastfeeding for 6months: An elicitation study. J Hum Nutr Diet [Internet]. 2009 [cited 2020 Dec 21];22(2):134-40. Available from: https://pubmed.ncbi.nlm.nih.gov/19302118/.

12. Mclnnes RJ, Chambers JA. Supporting breastfeeding mothers: Qualitative synthesis. J Adv Nurs [Internet]. 2008 May [cited 2020 Dec 23];62(4):407-27. Available from: https://pubmed.ncbi.nlm.nih.gov/18476941/.

13. Schmied V, Beake S, Sheehan A, McCourt C, Dykes F. Women's Perceptions and Experiences of Breastfeeding Support: A Metasynthesis. Birth [Internet]. 2011 Mar [cited 2020 Dec 23];38(1):49-60. Available from: https://pubmed.ncbi.nlm.nih.gov/21332775/. 
14. Battersby S. The role of the midwife in breastfeeding: Dichotomies and dissonance. Br J Midwifery [Internet]. 2014 Aug 1 [cited 2020 Dec 23];22(8):551-6. Available from: https://www.magonlinelibrary.com/doi/abs/10.12968/bjom.2014.22.8.551.

15. Lewin LO, O'Connor ME. "BreastfeedingBasics": Web-based education that meets current knowledge competencies. J Hum Lact [Internet]. 2012 Aug [cited 2020 Dec 26];28(3):407-13. Available from: https://pubmed.ncbi.nlm.nih.gov/22550095/.

16. Ahmed A, Bantz D, Richardson C. Breastfeeding knowledge of university nursing students. MCN Am J Matern Nurs [Internet]. 2011 Nov [cited 2020 Dec 26];36(6):361-7. Available from: https://pubmed.ncbi.nlm.nih.gov/22019915/.

17. Yang SF, Schmied V, Burns E, Salamonson Y. Breastfeeding knowledge and attitudes of baccalaureate nursing students in Taiwan: A cohort study. Women and Birth. 2019 Jun 1;32(3):e334-40.

18. Bäckström CA, Wahn EIH, Ekström AC. Two sides of breastfeeding support: Experiences of women and midwives. Int Breastfeed J [Internet]. 2010 Nov 29 [cited 2020 Dec 23];5. Available from: https://pubmed.ncbi.nlm.nih.gov/21114812/.

19. Nelson AM. Maternal-newborn nurses' experiences of inconsistent professional breastfeeding support. J Adv Nurs [Internet]. 2007 Oct [cited 2020 Dec 23];60(1):29-38. Available from: https://pubmed.ncbi.nlm.nih.gov/17824937/.

20. Verd S, De Sotto D, González T, Villalonga B, Moll J. Disparity between paediatricians' knowledge and practices regarding breastfeeding [3] [Internet]. Vol. 96, Paediatrica A, International Journal of Paediatrics. Acta Paediatr; 2007 [cited 2020 Dec 23]. p. 1712-3. Available from: https://pubmed.ncbi.nlm.nih.gov/17937698/.

21. Church S Midwives' personal experiences of pregnancy and childbirth: Exploring issues of autonomy and agency in relation to the use of professional knowledge [Internet]. Vol. 17, Human Fertility. Taylor \& Francis; 2014 [cited 2020 Dec 23]. p. 231-5. Available from: https://www.tandfonline.com/doi/abs/10.3109/14647273.2014.949879.

22. Furber $\mathrm{CM}$, Thomson AM. The emotions of integrating breastfeeding knowledge into practice for English midwives: A qualitative study. Int J Nurs Stud [Internet]. 2008 Feb [cited 2020 Dec 23];45(2):286-97. Available from: https://pubmed.ncbi.nlm.nih.gov/17049354/.

23. Marks D, O'Connor R. Health professionals' attitudes towards the promotion of breastfeeding. $\mathrm{Br} \mathrm{J}$ Midwifery [Internet]. 2015 Jan 1 [cited 2020 Dec 23];23(1):50-8. Available from: https://www.magonlinelibrary.com/doi/abs/10.12968/bjom.2015.23.1.50.

24. Guise JM, Freed G. Resident physicians' knowledge of breastfeeding and infant growth. Birth [Internet]. 2000 [cited 2020 Dec 23];27(1):49-53. Available from: https://pubmed.ncbi.nlm.nih.gov/10865561/.

25. Freed GL, Clark SJ, Sorenson J, Lohr JA, Cefalo R, Curtis P. National Assessment of Physicians' Breast-feeding Knowledge, Attitudes, Training, and Experience. JAMA J Am Med Assoc [Internet]. 
1995 Feb 8 [cited 2020 Dec 26];273(6):472-6. Available from:

https://pubmed.ncbi.nlm.nih.gov/7837365/.

26. Nakar S, Peretz O, Hoffman R, Grossman Z, Kaplan B, Vinker S. Attitudes and knowledge on breastfeeding among paediatricians, family physicians, and gynaecologists in Israel. Acta Paediatr [Internet]. 2007 May 24 [cited 2020 Dec 26];96(6):848-51. Available from: http://doi.wiley.com/10.1111/j.1651-2227.2007.00310.x.

27. Ingram J. Multiprofessional training for breastfeeding management in primary care in the UK. Int Breastfeed J [Internet]. 2006 Apr 28 [cited 2020 Dec 26];1(1):9. Available from: http://internationalbreastfeedingjournal.biomedcentral.com/articles/10.1186/1746-4358-1-9.

28. Finneran B, Murphy K. Breast is best for GPs-or is it? Breastfeeding attitudes and practice of general practitioners in the Mid-West of Ireland. Ir Med J. 2004 Oct;97(9):268-70.

29. Al-Nassaj HH, Al-Ward NJA, Al-Awqati NA. Knowledge, attitudes and sources of information on breastfeeding among medical professionals in Baghdad. Vol. 10, Eastern Mediterranean Health Journal. 2004.

30. Holtzman 0 , Usherwood T. Australian general practitioners' knowledge, attitudes and practices towards breastfeeding. PLoS One [Internet]. 2018 Feb 1 [cited 2020 Dec 27];13(2). Available from: https://pubmed.ncbi.nlm.nih.gov/29489841/.

31. Amir LH, Pirotta MV. Medicines for breastfeeding women: A postal survey of general practitioners in Victoria [Internet]. Vol. 191, Medical Journal of Australia. Australasian Medical Publishing Co. Ltd; 2009 [cited 2020 Dec 26]. p. 126. Available from: https://pubmed.ncbi.nlm.nih.gov/19619105/.

32. Brodribb W, Fallon A, Jackson C, Hegney D. Breastfeeding and Australian GP registrars - Their knowledge and attitudes. J Hum Lact. 2008;24(4):422-30.

33. Ahmed A, El Guindy SR. Breastfeeding knowledge and attitudes among Egyptian baccalaureate students. Int Nurs Rev [Internet]. 2011 Sep [cited 2020 Dec 27];58(3):372-8. Available from: https://pubmed.ncbi.nlm.nih.gov/21848786/.

34. Williams EL, Hammer LD. Breastfeeding attitudes and knowledge of pediatricians-in-training. Am J Prev Med. 1995;11(1):26-33.

35. Anchondo I, Berkeley L, Mulla ZD, Byrd T, Nuwayhid B, Handal G, et al. Pediatricians', obstetricians', gynecologists', and family medicine physicians' experiences with and attitudes about breast-feeding. South Med J [Internet]. 2012 May [cited 2020 Dec 27];105(5):243-8. Available from: https://pubmed.ncbi.nlm.nih.gov/22561534/.

36. Cricco-Lizza R. Student Nurses' Attitudes and Beliefs About Breast-Feeding. J Prof Nurs [Internet]. 2006 Sep [cited 2020 Dec 27];22(5):314-21. Available from: https://pubmed.ncbi.nlm.nih.gov/16990123/.

37. Spear HJ. Baccalaureate nursing students' breastfeeding knowledge: A descriptive survey. Nurse Educ Today [Internet]. 2006 May [cited 2020 Dec 27];26(4):332-7. Available from: https://pubmed.ncbi.nlm.nih.gov/16403591/. 
38. Freed GL, Jones TMI, Fraley JK. Attitudes and education of pediatric house staff concerning breastfeeding. South Med J [Internet]. 1992 [cited 2020 Dec 23];85(5):483-5. Available from: https://pubmed.ncbi.nlm.nih.gov/1585199/.

39. Power ML, Locke E, Chapin J, Klein L, Schulkin J. The effort to increase breast-feeding. Do obstetricians, in the forefront, need help? J Reprod Med. 2003 Feb;48(2):72-8.

40. Burt S, Whitmore M, Vearncombe D, Dykes $F$. The development and delivery of a practice-based breastfeeding education package for general practitioners in the UK. Matern Child Nutr [Internet]. 2006 Apr [cited 2020 Dec 27];2(2):91-102. Available from: https://pubmed.ncbi.nlm.nih.gov/16881919/.

41. Holmes AV, Mcleod AY, Thesing C, Kramer S, Howard CR. Physician breastfeeding education leads to practice changes and improved clinical outcomes. Breastfeed Med [Internet]. 2012 Dec 1 [cited 2020 Dec 27];7(6):403-8. Available from: https://pubmed.ncbi.nlm.nih.gov/23046226/.

42. Lawrence RA, Lawrence RM. Breastfeeding: A guide for the medical profession. 8th ed. Philadelphia: Elsevier Inc.; 2016. 992 p.

43. Chen $\mathrm{CH}$, Chen JY. Breastfeeding knowledge among health professionals in Taiwan. Acta Paediatr Taiwanica. 2004 Jul;45(4):208-12.

44. Barnett E, Sienkiewicz M, Roholt S. Beliefs About Breastfeeding: A Statewide Survey of Health Professionals. Birth [Internet]. 1995 [cited 2020 Dec 27];22(1):15-20. Available from: https://pubmed.ncbi.nlm.nih.gov/7741946/.

45. Brodribb W, Fallon A, Jackson C, Hegney D. The relationship between personal breastfeeding experience and the breastfeeding attitudes, knowledge, confidence and effectiveness of Australian GP registrars. Matern Child Nutr [Internet]. 2008 [cited 2020 Dec 27];4(4):264-74. Available from: https://pubmed.ncbi.nlm.nih.gov/18811791/.

46. Brodribb W, Fallon A, Jackson C, Hegney D. Breastfeeding and Australian GP registrars - Their knowledge and attitudes. J Hum Lact [Internet]. 2008 [cited 2020 Dec 26];24(4):422-30. Available from: https://pubmed.ncbi.nlm.nih.gov/18974291/.

47. Scott J, Mclnnes R, Tappin D, Guthrie E. Breastfeeding Opinions. Knowledge, Management Practices \& Training of Scottish Midwives [Internet]. Edinburgh; 2003 [cited 2020 Dec 27]. Available from: .

48. Kakrani VA, Rathod Waghela HK, Mammulwar MS, Bhawalkar JS. Awareness about "ten steps for successful breastfeeding" among medical and nursing students. Int J Prev Med [Internet]. 2015 [cited 2020 Dec 27];2015-May. Available from: https://pubmed.ncbi.nlm.nih.gov/26015863/.

49. Spatz DL, Pugh LC. The integration of the use of human milk and breastfeeding in baccalaureate nursing curricula. Nurs Outlook [Internet]. 2007 Sep [cited 2020 Dec 27];55(5):257-63. Available from: https://pubmed.ncbi.nlm.nih.gov/17950120/.

50. Spatz DL. The breastfeeding case study: A model for educating nursing students. J Nurs Educ [Internet]. 2005 Sep 1 [cited 2020 Dec 27];44(9):432-4. Available from: https:// europepmc.org/article/med/16220652. 
51. Deloian BJ, Lewin LO, O'Connor ME. Use of a web-based education program improves nurses' knowledge of breastfeeding. JOGNN - J Obstet Gynecol Neonatal Nurs [Internet]. 2015 Jan 1 [cited 2020 Dec 27];44(1):77-86. Available from: https://pubmed.ncbi.nlm.nih.gov/25580851/.

52. Vandewark AC. Breastfeeding Attitudes and Knowledge in Bachelor of Science in Nursing Candidates. J Perinat Educ [Internet]. 2014 [cited 2020 Dec 27];23(3):135-41. Available from: https://pubmed.ncbi.nlm.nih.gov/25364217/.

53. WHO. Baby-Friendly Hospital Initiative. WHO [Internet]. 2018 [cited 2020 Dec 27]; Available from: http://www.who.int/nutrition/publications/infantfeeding/bfhi_trainingcourse/en/.

54. Australian College of Midwifes. BFHI Handbook for Maternity Facilities. 2016.

55. Yang SF, Salamonson Y, Burns E, Schmied V. Breastfeeding knowledge and attitudes of health professional students: A systematic review [Internet]. Vol. 13, International Breastfeeding Journal. BioMed Central Ltd.; 2018 [cited 2020 Dec 26]. p. 8. Available from: https://internationalbreastfeedingjournal.biomedcentral.com/articles/10.1186/s13006-018-0153-1.

56. Cianelli R, Villegas N, Azaiza K, Henderson S, Hooshmand M, Peragallo N. Developing and testing an online breastfeeding training among undergraduate nursing students. Clin Nurs Stud [Internet]. 2014 Nov 30 [cited 2020 Dec 27];3(1):82. Available from: /pmc/articles/PMC5069066/?report = abstract.

57. Dodgson JE, Tarrant M. Outcomes of a breastfeeding educational intervention for baccalaureate nursing students. Nurse Educ Today [Internet]. 2007 Nov [cited 2020 Dec 27];27(8):856-67. Available from: https://pubmed.ncbi.nlm.nih.gov/17257711/. 